\title{
On-farm biosecurity as perceived by professionals visiting Swedish farms
}

\author{
Maria Nöremark ${ }^{1 *}$ and Susanna Sternberg-Lewerin ${ }^{2}$
}

\begin{abstract}
Background: On-farm biosecurity is an important part of disease prevention and control, this applies to live animal contacts as well as indirect contacts e.g. via professionals visiting farms in their work. The objectives of this study were to investigate how professionals visiting animal farms in Sweden in their daily work perceive the on-farm conditions for biosecurity, the factors that influence their own biosecurity routines and what they describe as obstacles for biosecurity. Suggestions for improvements were also asked for. Questionnaires were distributed to professionals visiting farms in their daily work; veterinarians, livestock hauliers, artificial insemination technicians, animal welfare inspectors and cattle hoof trimmers. The sample was a convenience sample, based on accessibility to registers or collaboration with organisations distributing the questionnaire. Respondents were asked about the availability of certain biosecurity conditions related to farm visits, e.g. if facilities for hand washing were available, how important different factors were for their own routines and, through open ended questions, to describe obstacles and suggestions for improvement.
\end{abstract}

Results: After data cleaning, there were responses from 368 persons. There was a difference in the proportion of visited farms reported to have certain biosecurity measures in place related to animal species present on the farm. In general, visited pig farms had a higher proportion of biosecurity measures in place, whereas the conditions were poorer on sheep and goat farms and horse farms. There were also differences between the visitor categories; the perceived conditions for biosecurity varied between the groups, e.g. livestock hauliers did not have access to hand washing facilities as often as veterinarians did. In all groups, a majority of the respondents perceived obstacles for on-farm biosecurity, among veterinarians $66 \%$ perceived that there were obstacles. Many of the reported obstacles related to the very basics of biosecurity, such as access to soap and water. Responsibility was identified to be a key issue; while some farmers expect visitors to take responsibility for keeping up biosecurity they do not provide the adequate on-farm conditions.

Conclusions: Many of the respondents reported obstacles for keeping good biosecurity related to on-farm conditions. There was a gap when it came to responsibility which needs to be clarified. Visitors need to take responsibility for avoiding spread of disease, while farmers need to assume responsibility for providing adequate conditions for on-farm biosecurity.

\section{Background}

Indirect contacts via visitors can play a role in the spread of both endemic and exotic diseases. Adequate biosecurity routines can minimize the risk of such spread, e.g. using clean boots and protective clothing and cleaning equipment between farms. Correspondingly, a lack of biosecurity can contribute to the spread of disease [1-6].

\footnotetext{
* Correspondence: maria.noremark@sva.se

'Department of Disease Control and Epidemiology, SVA, National Veterinary Institute, Uppsala SE-751 89, Sweden

Full list of author information is available at the end of the article
}

The importance of farm biosecurity has been highlighted during the last decade; within the European Union (EU) the proposal for a new animal health law emphasises biosecurity [7] and a number of studies with focus onfarm biosecurity have been published [3,8-20]. Specifically related to farm visits and biosecurity for visitors, Racicot and co-authors have in a series of studies analyzed biosecurity errors while entering farms and factors affecting compliance with routines, e.g. personality traits and education [21-23].
() Biomed Central

(c) 2014 Nöremark and Sternberg-Lewerin; licensee BioMed Central Ltd. This is an Open Access article distributed under the terms of the Creative Commons Attribution License (http://creativecommons.org/licenses/by/2.0), which permits unrestricted use, distribution, and reproduction in any medium, provided the original work is properly credited. 
In a previous study conducted in Sweden [24], disparities were found in biosecurity routines between farmers with different species and different herd sizes. The farmers also reported a difference in the biosecurity routines applied by different categories of professional visitors coming to their farms, for example livestock hauliers, veterinarians and inspectors. Some farmers reported that they had different requirements for biosecurity depending on type of visitor. Moreover, some farmers reported that they did not consider biosecurity necessary unless there were current outbreaks of exotic diseases in the country. When working with outbreak investigations, the authors have experienced that professional visitors sometimes adapt their routines depending on the farmers' requirements, the same person can thus have very different routines in different farms. This interaction between the farmer and the visitor is part of the complexity related to the on-farm biosecurity applied by visitors. Several different factors could influence the intended behaviour of the visitor, such as the requirements from their own organization and their own will not to spread disease. But regardless of the visitors' own intentions, the practical and physical conditions provided on the farms, as well as requirements, or lack thereof, from the farmers, will probably affect what is actually done on each farm. Practical obstacles can impair the intended behaviour. If the visitor does not have access to running water while on the farm, washing the boots before leaving will be difficult. In a Canadian study it was shown that design of the hygiene barrier affected the number of biosecurity errors made by visitors [22].

Although many diseases are species specific, this does not apply to all diseases. Some visitors, e.g. veterinarians, often visit many different categories of farms and could potentially spread disease between different species or different categories of the population. If the routines for biosecurity are inferior in one type of species, this could thus impact spread of disease to other species. Some of the diseases are also zoonotic; several studies have identified a higher prevalence of zoonotic diseases among veterinarians, and concern among veterinarians for contracting zoonotic infections has also been investigated [25-28].

In Sweden, as well as in other parts of the EU, several projects are currently underway to improve on-farm biosecurity routines, decrease the risk of spread of endemic livestock diseases and decrease the risk of outbreaks of exotic diseases. The proposal for a new EU Animal Health Law puts more responsibility for disease prevention on the farmers and, consequently, a high level of on-farm biosecurity will be required when the regulation comes into force [7].

The objectives of this study were to investigate how professionals visiting farms with animals in Sweden in their daily work perceive the on-farm conditions for biosecurity, the factors that influence their own biosecurity routines and what they describe as obstacles for biosecurity, and to collect suggestions for improvements. The aim is to use the information as a basis for future work in improving on-farm biosecurity and biosecurity among professional visitors.

\section{Methods}

\section{Sample and distribution of questionnaire}

Data in this study were gathered through questionnaires sent to five categories of professionals that regularly visit farms in their work. These were; veterinarians, livestock hauliers, artificial insemination (AI) technicians, animal welfare inspectors and cattle hoof trimmers. This sample was a convenience sample of groups where some kind of contact information or distribution channel was found. The chosen categories were either included in an accessible official register (livestock hauliers), or were part of organizations that were willing to distribute the questionnaire among their employees or members (veterinarians, AI-technicians, animal welfare inspectors), or had contact information available on websites (hoof trimmers). For this reason the exact number of persons receiving the questionnaires within each category is not known. For veterinarians, e-mail questionnaires were distributed by the two Swedish veterinary unions (without indicating the exact number of recipients, one of the unions reported they sent to all members and the other one to members of the sections for livestock and horse practitioners). Livestock hauliers were identified through an official register held by the Swedish Board of Agriculture and were sent the questionnaire either via e-mail $(n=104)$, in paper format $(n=40)$, or both paper and e-mail $(n=35)$ depending on the data received from the register; not all livestock hauliers had e-mail addresses. Three AI companies, one national and two regional, distributed the electronic version of the questionnaire among their employees (the exact number of recipients is not known). Animal welfare inspectors in Sweden work in the County Administrative Boards, and were contacted through the network of the heads of animal welfare in these authorities. The questionnaire was distributed within their network and redistributed at regional level by their contact points (exact number of recipients is therefore not known). Cattle hoof trimmers were identified through a cattle hoof trimmers organization webpage and, after a search of addresses using an internet search engine, questionnaires were sent to all e-mail addresses obtained $(n=57)$. The questionnaires were distributed between May and December 2012. An invitation letter was attached to the questionnaire which explained the background of the study, clarified that answers would be treated anonymously and encouraged participation. Reminders were sent to hoof trimmers and some of the livestock hauliers for which there was direct 
access to the e-mail addresses. Since other groups received the questionnaire through their organisations, sometimes forwarded in several steps, reminders were not sent to these groups.

The first section of questions related to the on-farm conditions. Respondents were asked to give the proportions of farms they visit that have; hygiene barrier, protective clothing for visitors, hand-washing facilities, hand disinfection, and requirements as regards to the use of protective clothing. These questions were split by species present on the farms (cattle, pigs, sheep/goats, horses) and respondents were asked to respond only for the farms that they normally visit in their daily work. Livestock hauliers were also asked how often they needed to enter animal buildings. The second part of the questions related to the visitors' own routines; how important different factors were for their routines, and the proportion of visits when they applied different routines. The third, and last, part consisted of open ended questions. Respondents were asked if there were any diseases that they in their profession were afraid to spread between farms or contract themselves. Finally they were asked about obstacles for biosecurity and factors for improving biosecurity, both on farm level and within their own profession. The questionnaire also included background questions on profession, age, number of farms visited per week. The questionnaire is available as Additional file 1 (in English) and Additional file 2 (in Swedish). Before sending the questionnaire, a pilot version was tested on 14 veterinarians working in the National Veterinary Institute. The group was a mixture of persons with recent experience of working in the field and visiting farms on a daily basis, with expertise in biosecurity or with experience in questionnaire design. Data from the paper questionnaires were entered manually into the electronic version of the questionnaire, data entry was checked for consistency.

\section{Analysis}

The data were checked and cleaned; data from respondents that were not part of the intended study population were dropped. Descriptive statistics were obtained for all closed questions, both total and by categories of visitors. The responses to all open questions were read separately by the two authors, who created different categories representing the different types of responses. These categories were thereafter compared and merged into a single list by the two researchers. Each response was then assigned into one or more of the categories, this was also done separately by the two authors and the results were then checked for consistency. Whenever there was a discrepancy, this was discussed and the response was assigned to one of the categories. Finally, the frequency of the different response categories was calculated. Some replies were combined, for example, 'MRSA' (Methicillin resistant Staphylococcus aureus) were combined with 'multiresistant bacteria', thus anyone replying both 'MRSA' and 'multiresistant bacteria' contributed only once to 'multiresistant bacteria or MRSA'.

\section{Software used}

The questionnaire was designed and administered using the web survey software Easyresearch (QuestBack International HQ, Oslo, Norway). Data were analysed using STATA 11.2 (Stata Co., College Station, Texas, USA), graphs were drawn using Microsoft Office Excel 2007 (Microsoft Co., Redmond, USA).

\section{Results}

\section{Response rate}

The numbers of respondents (to the entire or part of the questionnaire) after data cleaning were; 188 veterinarians, 82 animal welfare inspectors, 59 AI-technicians, 28 livestock hauliers and 11 cattle hoof trimmers, in total 368. Seven respondents were dropped during data cleaning because they either did not visit farms, worked abroad or belonged to a profession that was not included in the sample. The age of the respondents was as follows; $20 \%$ were 20-35 years, 35\% 36-50, 41\% 51-65 and 4\% >66 years. The age varied between the groups; $63 \%$ of the AItechnicians, $52 \%$ of the hauliers and $51 \%$ of veterinarians were above 50 years of age, while only $36 \%$ of the hoof trimmers and $17 \%$ of the inspectors were above 50 years of age. Since the sample was a convenience sample and data collection relied on the collaboration with organizations and their willingness to distribute the questionnaire, the number of persons that received the questionnaire within each category for veterinarians, AI-technicians and animal welfare inspectors was not known. For the categories with direct access to e-mail addresses; cattle hoof trimmers and some of the livestock hauliers, the response-rate was low and some e-mails also bounced, indicating the addresses were no longer in use. For hoof trimmers $27 \%$ of the addresses bounced and based on the addresses that did not bounce, the response rate was $17 \%$. For the livestock hauliers that only received the questionnaire through e-mail, $21 \%$ of the addresses bounced and the response rate was $5 \%$. However, for the paper questionnaires to livestock hauliers the response rate was $27 \%$.

\section{Descriptive statistics}

Cattle farms were visited by most respondents (86\%), while pig farms were visited by the least (43\%). The number of farms visited varied, with hauliers and AI-technicians visiting most farms; $56 \%$ and $69 \%$ of them visited more than 20 farms per week (Table 1).

The reported on-farm biosecurity differed depending on species present on the farm (Table 2). In general, the highest proportion of biosecurity measures related to 
Table 1 Types of farms visited and number of farms visited per week by professionals responding to the questionnaire

\begin{tabular}{|c|c|c|c|c|c|c|c|c|c|}
\hline \multirow[b]{2}{*}{ Category of visitor } & \multicolumn{4}{|c|}{$\begin{array}{c}\text { Proportion* of respondents reporting to visit } \\
\text { each type of farm (\%) }\end{array}$} & \multicolumn{4}{|c|}{$\begin{array}{l}\text { Number of farms reported to be } \\
\text { visited per week (\%) }\end{array}$} & \multirow[b]{2}{*}{$\mathbf{n}$} \\
\hline & Cattle & Pig & Sheep/goat & Horse & $<1$ & $1-10$ & $11-20$ & $>20$ & \\
\hline Veterinarian & 77 & 33 & 57 & 87 & 12 & 46 & 34 & 9 & 181 \\
\hline Al-technician & 100 & 15 & 0 & 3 & 2 & 5 & 24 & 69 & 59 \\
\hline Animal transporter & 82 & 71 & 68 & 21 & 0 & 11 & 33 & 56 & 27 \\
\hline Inspector & 96 & 79 & 96 & 95 & 10 & 89 & 0 & 1 & 81 \\
\hline Cattle hoof trimmer** & 90 & 27 & 9 & 9 & 9 & 81 & 9 & 0 & 11 \\
\hline Total & 86 & 43 & 56 & 68 & 9 & 47 & 24 & 20 & 359 \\
\hline
\end{tabular}

*One or more type could be indicated by the respondent. **One cattle hoof trimmer worked with species other than cattle.

farm visits were reported to be in place on pig farms, followed by cattle farms. Farms with small ruminants or horses were reported to have less biosecurity measures in place. On these farms it was reported that there was seldom access to protective clothing or boots for the visitors, or even possibility for hand washing. Among veterinarians, a group in close contact with sick animals, 24\% $(\mathrm{n}=152)$ reported that hand washing facilities were available on none or almost none of the horse farms they visit. The corresponding figure for sheep farms was $31 \%(n=100)$. There were also reported differences within the same farm types, i.e. different categories of visitors reported different proportions of certain biosecurity measures to be present on the farms they visit. This is illustrated through one example in Figure 1, showing availability of hand washing facilities on cattle farms. A clear majority of veterinarians and AI-technicians reported this to be available on all or almost all cattle farms they visit, which was in clear contrast to inspectors and livestock hauliers. A similar picture was also seen in pig farms. Among the veterinarians, $49 \%(n=57)$ reported they could wash their hands on all pig farms they visit, but only $6 \%(n=17)$ of the hauliers. In fact, $35 \%$ of the livestock hauliers reported they could wash their hands on none or almost none of the pig farms they visited. A clear difference was also seen for availability of protective clothing in cattle herds, where $81 \%(n=21)$ of the hauliers reported protective clothing to be available on none or almost none of the cattle farms they visited, but only $21 \%(n=57)$ of the AI-technicians reported it to be available on almost none of the farms $(0 \%$ answered 'none'). Corresponding patterns for protective clothing were seen on pig farms when comparing livestock hauliers and veterinarians; $41 \%$ of hauliers $(n=17)$ and $11 \%$ of veterinarians $(n=56)$ reported protective clothing to be available on none or almost none of the farms. Similar patterns were seen when comparing reported availability of boots for visitors both on cattle and pig-farms. On cattle farms $76 \%(n=21)$ of the hauliers, $44 \%(n=133)$ of the veterinarians and $37 \%(n=59)$ of the AI-technicians reported that boots were available on none or almost none of the farms. For pig farms $63 \%(n=57)$ of the veterinarians and $6 \%$ of the hauliers $(n=18)$ reported boots to be available on all or almost all farms.

When it came to biosecurity requirements made by farmers, there was also a perceived difference between the groups of visitors with $73 \%(n=22)$ of hauliers reporting that none or almost none of cattle farmers they visit have any biosecurity requirements, whereas the other professionals reported a higher proportion of cattle farmers requiring biosecurity measures. Requirements also differed between animal species on the farms. Hauliers reported 38\% $(n=16)$ of pig farmers to have biosecurity requirements. Of the veterinarians, $75 \%$ $(\mathrm{n}=152)$ reported that none of the horse farms they visit have biosecurity requirements.

As for entering the farm buildings (a question that was specifically asked to livestock hauliers since they sometimes enter farms), there was a difference between pig farms compared to cattle, sheep and goat farms. Only $4 \%$ reported that they entered almost all pig farms (noone wrote they entered all pig farms) whereas $43 \%$ wrote they entered all or almost all cattle farms and $39 \%$ that they entered all or almost all sheep and goat farms $(\mathrm{n}=28)$.

For the factors affecting their own biosecurity routines, all categories of visitors had a high proportion of respondents reporting that 'their own will not to spread disease' $(82-96 \%$, total $95 \% \mathrm{n}=345)$ and 'current disease outbreaks' $(91-95 \%$, total $93 \% \mathrm{n}=341)$ were very important for their routines. Animal species present on the farm and herd size were regarded as very important by $28 \%(n=336)$ and $15 \%(n=343)$ of the respondents respectively. Again, there was a difference between groups. Only $4 \%(n=28)$ of the livestock hauliers reported 'farmers' requests on biosecurity' to be 'irrelevant' or 'less important' for their routines, whereas the corresponding figure for the inspectors was $35 \%(n=77)$. Among both the AI-technicians $(n=57)$ and the hoof-trimmers $(n=11) 91 \%$ reported that the "market advantage of keeping a good hygiene" was "quite important' or 'very important' for their routines, compared to $59 \%(n=170)$ of the veterinarians. 
Table 2 Proportion of Swedish farms visited by professionals in their work reported to have certain biosecurity measures in place

$$
\% \text { responses in each category }
$$

\begin{tabular}{|c|c|c|c|c|c|c|c|c|}
\hline Question & All & Almost all & More than half & Approximately half & Less than half & Almost none & None & $\mathbf{n}$ \\
\hline \multicolumn{9}{|c|}{ When visiting farms, proportion of farms that have: } \\
\hline \multicolumn{9}{|l|}{ Hygiene barrier } \\
\hline Pig farms & 15.4 & 33.1 & 13.2 & 10.3 & 9.6 & 14.0 & 4.4 & 136 \\
\hline Cattle farms & 0.7 & 7.2 & 3.2 & 3.2 & 18.7 & 44.6 & 22.3 & 278 \\
\hline Sheep/goat farms & 0 & 1.1 & 0 & 0 & 7.3 & 37.2 & 54.5 & 191 \\
\hline Horse farms & 0 & 0 & 0.4 & 0 & 1.3 & 14.8 & 83.5 & 230 \\
\hline \multicolumn{9}{|c|}{ Protective clothing for visitors } \\
\hline Pig farms & 18.0 & 25.0 & 16.4 & 5.5 & 11.7 & 14.8 & 8.6 & 128 \\
\hline Cattle farms & 0.4 & 11.0 & 4.2 & 6.0 & 26.2 & 35.3 & 17.0 & 283 \\
\hline Sheep/goat farms & 0 & 0 & 0.5 & 0 & 4.3 & 30.8 & 64.3 & 185 \\
\hline Horse farms & 0 & 0 & 0 & 0 & 0 & 9.0 & 91.0 & 234 \\
\hline \multicolumn{9}{|l|}{ Boots for visitors } \\
\hline Pig farms & 18.6 & 24.8 & 14.0 & 6.2 & 10.1 & 17.8 & 8.5 & 129 \\
\hline Cattle farms & 0.4 & 1.7 & 4.8 & 6.6 & 30.5 & 39.8 & 16.3 & 289 \\
\hline Sheep/goat farms & 0 & 0 & 0 & 0 & 4.3 & 28.1 & 67.6 & 185 \\
\hline Horse farms & 0 & 0 & 0 & 0 & 0.0 & 7.4 & 92.6 & 231 \\
\hline \multicolumn{9}{|c|}{ Facilities for hand washing } \\
\hline Pig farms & 28.4 & 33.6 & 13.4 & 3.0 & 11.2 & 7.5 & 3.0 & 134 \\
\hline Cattle farms & 28.0 & 37.8 & 7.4 & 9.1 & 9.1 & 6.1 & 2.4 & 296 \\
\hline Sheep/goat farms & 1.6 & 10.2 & 6.4 & 10.7 & 21.9 & 34.2 & 15.0 & 187 \\
\hline Horse farms & 1.7 & 8.2 & 6.5 & 22.1 & 29.9 & 19.9 & 11.7 & 231 \\
\hline \multicolumn{9}{|l|}{ Hand disinfection } \\
\hline Pig farms & 4.4 & 10.6 & 7.1 & 5.3 & 13.3 & 36.3 & 23.0 & 113 \\
\hline Cattle farms & 1.1 & 1.1 & 3.2 & 5.7 & 15.0 & 48.2 & 25.7 & 280 \\
\hline Sheep/goat farms & 0 & 0.6 & 0.6 & 1.7 & 4.6 & 25.6 & 67.1 & 176 \\
\hline Horse farms & 0 & 0.5 & 0 & 2.3 & 5.4 & 28.4 & 63.5 & 222 \\
\hline \multicolumn{9}{|c|}{ Proportion of the farmers who require that visitors use protective clothing: } \\
\hline Pig farms & 27.9 & 32.6 & 7.8 & 12.4 & 6.2 & 8.5 & 4.7 & 129 \\
\hline Cattle farms & 8.4 & 20.9 & 10.6 & 7.0 & 16.5 & 28.9 & 7.7 & 273 \\
\hline Sheep/goat farms & 0.6 & 2.9 & 4.6 & 9.2 & 12.6 & 35.6 & 34.5 & 174 \\
\hline Horse farms & 0.4 & 0 & 0 & 0.9 & 2.6 & 29.2 & 67.0 & 233 \\
\hline
\end{tabular}

Based on a questionnaire to veterinarians, Al-technicians, animal welfare inspectors, livestock hauliers and hoof trimmers in $2012-2013$.

There was also a difference between groups whether they had asked the farmer to improve the routines or not, with veterinarians being the group most often $(56 \%$, $\mathrm{n}=186$ ) reporting that they had asked farmers to improve the farm conditions for biosecurity for visitors 'many times'. Only $11 \%(n=28)$ of the livestock hauliers had asked this 'many times'. Among the inspectors, $60 \%$ $(\mathrm{n}=82)$ had never asked farmers to improve the onfarm conditions for visitors' biosecurity.

When assessing their own routines, $18 \%$ considered them to be 'very good', $58 \%$ 'sufficient', $8 \%$ 'insufficient' and $16 \%$ said this varied between farms $(\mathrm{n}=343)$.

When looking at the perceived risk of spreading or contracting disease, there were also differences between the groups. In all groups, a majority (by group $54-87 \%$; total $76 \%, \mathrm{n}=338$ ) reported that there were infectious agents that they were afraid to spread between farms, with the highest number among veterinarians $(87 \%, n=146)$. For all the groups, there were higher proportions reporting they were afraid to spread disease, as compared to contracting disease themselves (21-63\%, total $44 \%, \mathrm{n}=340)$. Among the respondents being afraid to spread or contract diseases, 205 gave examples of what they were afraid to spread (Table 3), and 128 gave examples of what they were afraid to contract (Table 4). The infections that the visitors were most afraid to spread between farms were; salmonellosis and ringworm followed by strangles and less well specified infections such as 'diarrhoea', 'viral diseases', and 


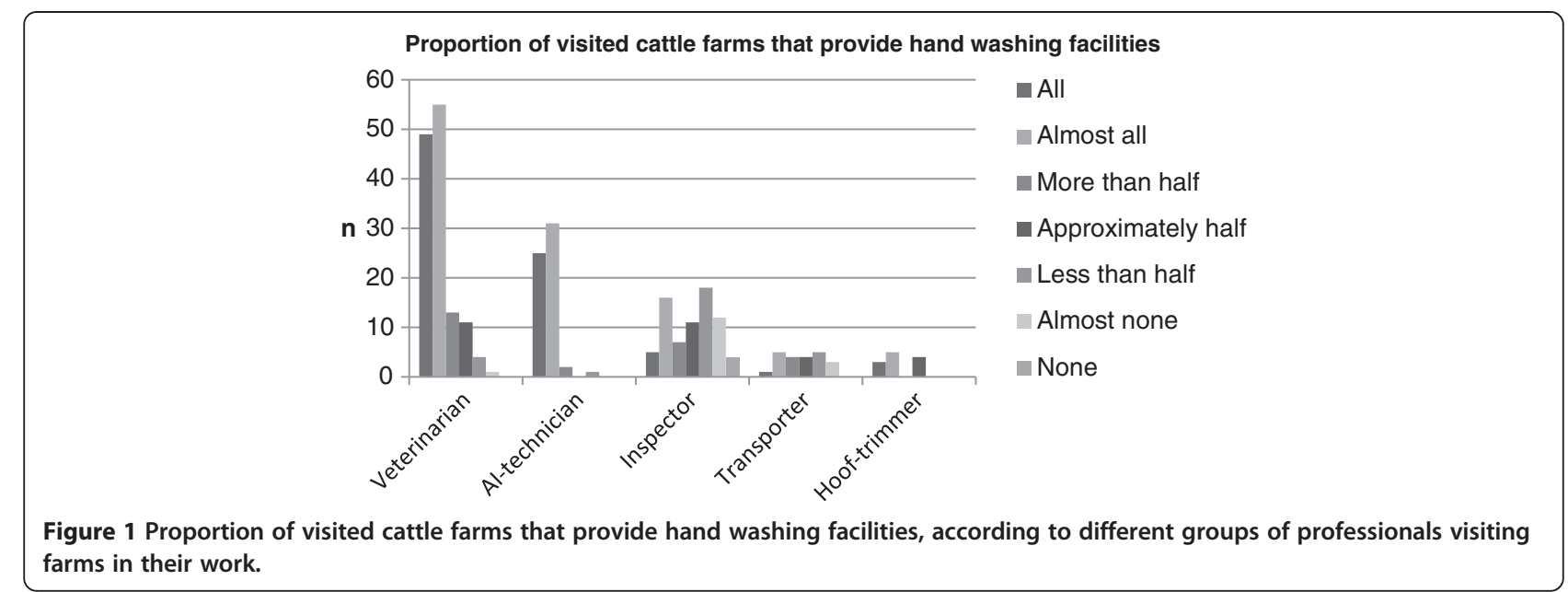

Table 3 Infectious agents or diseases professionals visiting farms in their work reported to be afraid to spread

\begin{tabular}{ll}
\hline $\begin{array}{l}\text { Infectious agents or disease-conditions } \\
\text { professionals visiting farms in their work } \\
\text { reported to be afraid to spread }\end{array}$ & $\begin{array}{l}\text { Number of } \\
\text { times stated }\end{array}$ \\
\hline Salmonella & 72 \\
\hline Ringworm & 59 \\
\hline Diarrhoeal diseases & 57 \\
\hline Strangles & 50 \\
\hline Viral diseases & 40 \\
\hline Respiratory diseases & 35 \\
\hline Respiratory syncytial virus & 22 \\
\hline Everything & 20 \\
\hline Corona virus & 19 \\
\hline Equine influenza & 15 \\
\hline MRSA, multiresistant bacteria, ESBL & 15 \\
\hline BVDV & 14 \\
\hline Equine herpes virus & 13 \\
\hline Influenza & 11 \\
\hline VTEC/EHEC & 8 \\
\hline Ongoing infections & 7 \\
\hline Epizootic diseases & 6 \\
\hline Equine viral diseases & 6 \\
\hline Foot rot & 5 \\
\hline Unknown diseases & 5 \\
\hline Other* & 62 \\
\hline Based on an open nded & 20 . \\
\hline
\end{tabular}

Based on an open ended question in a questionnaire to Swedish veterinarians, Al-technicians, animal welfare inspectors, livestock hauliers and hoof trimmers in 2012-2013. Responders were asked to give examples (without ranking) of diseases they were afraid to spread in their work.

In total 205 responders gave one or more examples of what they were afraid to spread (121 veterinarians, 38 Al-technicians, 26 inspectors, 11 hauliers, 9 hoof trimmers) *Other = disease or disease condition reported by less than five responders, e.g.: Bacterial diseases; Mastitis; Swine dysentery; Digital dermatitis; Maedi Visna; PRRS; APP; Fusobacterium necroforum; Flees; Papilloma virus; Q-fever; Swine influenza; BSE; CEM; Circo virus; Malignant catarrhal fever; Lawsonia intracellularis; Bovine leukosis; Foot- and mouth disease; Rhinovirus; Rota virus; Erysepelotrix rhusopatie; SEP, Scabies, Streptococci. 'respiratory diseases'. The same two infections, but in reversed order were in the two top positions for what the visitors were afraid to contract; ringworm first and in second place salmonellosis. These were followed by multiresistant bacteria and MRSA, EHEC, and listeriosis.

In total approximately half $(52 \%, \mathrm{n}=338)$ of the respondents reported that there were obstacles to keeping a high level of biosecurity during farm visits. The number of respondents reporting obstacles was clearly highest among the veterinarians; $66 \%(n=169)$ compared to $33-40 \%$ among the other groups. Of the respondents, 178 gave examples of obstacles and the majority of the

Table 4 Infectious agents or disease-conditions professionals visiting farms in their work reported to be afraid to contract

\begin{tabular}{ll}
\hline $\begin{array}{l}\text { Infectious agent, disease or condition } \\
\text { responders were afraid to contract }\end{array}$ & $\begin{array}{l}\text { Number of } \\
\text { times stated }\end{array}$ \\
\hline Ringworm & 55 \\
\hline Salmonella & 39 \\
\hline MRSA, Multi-resistant bacteria and ESBL & 22 \\
\hline EHEC & 21 \\
\hline Listeriosis & 10 \\
\hline Q-fever & 6 \\
\hline Rabies & 6 \\
\hline Wound infections & 5 \\
\hline Toxoplasmosis & 5 \\
\hline Diseases that are a risk when pregnant & 5 \\
\hline Other* & 41
\end{tabular}

Based on an open ended question in a questionnaire to Swedish veterinarians, Al-technicians, animal welfare inspectors, livestock hauliers and hoof trimmers in 2012-2013. Responders were asked to give examples (without ranking) of diseases they were afraid to contract in their work.

In total, 128 responders ( 73 veterinarians, 25 Al-technicians, 18 inspectors, 7 hoof-trimmers, 5 hauliers) gave one or more examples ${ }^{*}$ Other $=$ disease or disease condition reported by less than five responders, e.g.: Bacteria; Tuberculosis; Anthrax; Campylobacter; Cryptosporidium; Orf; Mycoplasma; Scabies, Intestinal bacteria; Toxocara cati; Diseases related to abortion. 
examples (213) were related to conditions on the farm (Table 5). With the number one being 'Lack of water, soap, wash basin, paper towels', followed by 'Inadequate equipment or lack of water to clean boots or equipment' and in third place 'Adequate protective clothing not available on the farm; non-existing, cold, dirty or wrong size'. There were also obstacles related to the working situation (22); 'Lack of time, the working schedule does not allow adequate cleaning between farms' or 'Inadequate protective clothes, or not as many as needed provided by the employer'. Also for the suggestions on improvement (Table 6), measures related to conditions on the farm dominated (235) followed by measures related to communication (84). For the farm related suggestions, most related to 'Protective clothing made available on-

Table 5 Reported obstacles for on-farm biosecurity reported by professionals visiting farms in their work

Reported obstacles for on-farm biosecurity

Lack of water, soap, wash basin, paper-towels ( $f$ )

81

Inadequate equipment or lack of water to clean boots or equipment (f)

Adequate protective clothing not available on the farm; non-existing, cold, dirty or wrong size ( $f$ )

Lack of time, the working schedule does not allow adequate cleaning between farms

No hygiene barrier or inadequate separation of clean and dirty areas (e.g. have to pass dirty area after washing) (f)

Sensitive equipment (e.g. handheld computer) is difficult to clean

Ignorance, unwillingness or unawareness among the farmers

No clean surfaces for equipment, e.g. no clean table for the veterinary medical equipment $(f)$

Cold climate makes it difficult to change on-farm, cause chapped hands, shoe covers are slippery on snow and ice, water freezes when washing equipment

No hand disinfectant available on-farm ( $f$ )

Lack of space in the car (w)

Inadequate protective clothes, or not as many as needed provided 6 by the employer $(\mathrm{w})$

Lack of general hygiene on-farm (f)

Other*

Based on an open ended question in a questionnaire to Swedish veterinarians, Al-technicians, animal welfare inspectors, livestock hauliers and hoof trimmers in 2012-2013.

$(\mathrm{f})=$ farm related,$(\mathrm{w})=$ workplace related

*Other = Obstacles reported by less than five responders, e.g.: Dirty yard; If demands are too high, one risks to be regarded as uncomfortable and the farmer will turn to someone else instead; Standard protective coat scares some horses; No separate out load area for dispatched animals; The farmers are afraid of the animals and cannot load them; Distance prevents planning of trips based on biosecurity levels; Design of the building; The farmer does not inform about current disease situation on the farm; Lack of resources (money); Shared vehicles; Disposable shoe protections of poor quality; Lack of guidelines on national level for farmers and professionals visiting farms in their work/the requirements are too low; Lack of hygiene education; Inadequate handling of laundry, protective clothing are re-contaminated; Difficult to find adequate protective clothing for cold winter climate; Animal welfare inspection visits often have a negative effect on the mood and attitude of the farmer and this makes biosecurity more difficult. farm; clean, warm and of adequate size' (65), followed by 'Warm water, soap, wash basin and paper-towels available on-farm' (57) and 'Hard surface and water hose with adequate pressure available on the farm to clean boots and equipment, adequately located' (34). Regarding communications there were suggestions on 'Information to farmers, making farmers more aware, active dialogue with farmers, move the responsibility to the farmers' (58) as well as 'National biosecurity guidelines for both farmers and professionals' (9).

In addition to the open ended questions, many of the respondents had written comments to the other questions (not included in the tables). Many of the comments gave additional information to the answers given and some comments clarified specific problems faced by certain groups of visitors. For example, the inspectors wrote that they always brought their own clean protective clothing, i.e. there was seldom need either for farmers to request more from them or, for them to ask the farmer for better conditions. Inspectors were also very concerned not to spread disease, expressing worries that it would give the inspectors as a group a bad reputation if they did. There were also comments related to how their task affected their work, and that they could experience threatening situations that sometimes affected the possibility to keep up good biosecurity. For cattle farms, there were many comments emphasising the difference between dairy herds and beef herds, where the biosecurity was perceived as better in the dairy herds. Related to pig herds there were comments that they in general were better compared to other species, but also that the routines were better while the eradication programme against Aujeszky's disease was still ongoing. There were also comments stating that farmers in general, and even horse owners, almost always provided soap, warm water and towels twenty years ago, while this was less common nowadays. Regarding the horse stables, there were numerous comments about non-existing biosecurity, horse owners questioning the need for hand wash or protective clothing as well as comments related to horses being scared of the ordinary coats. Several veterinarians reported not using protective coats when treating horses for this reason. The status of the protective clothing provided by farmers generated many comments. In addition to recurrent comments about wet, cold and dirty clothes there were also comments about boots containing rat's nests, mouse droppings or spider webs.

\section{Discussion}

Many of the respondents experienced obstacles for on-farm biosecurity, a remarkable number of the reported obstacles related to the very basics of biosecurity. Some respondents described a worsening situation. Sweden has historically had a strategy to control and eradicate diseases 
Table 6 Reported suggestions for improvement of on-farm biosecurity reported by professionals visiting farms in their work

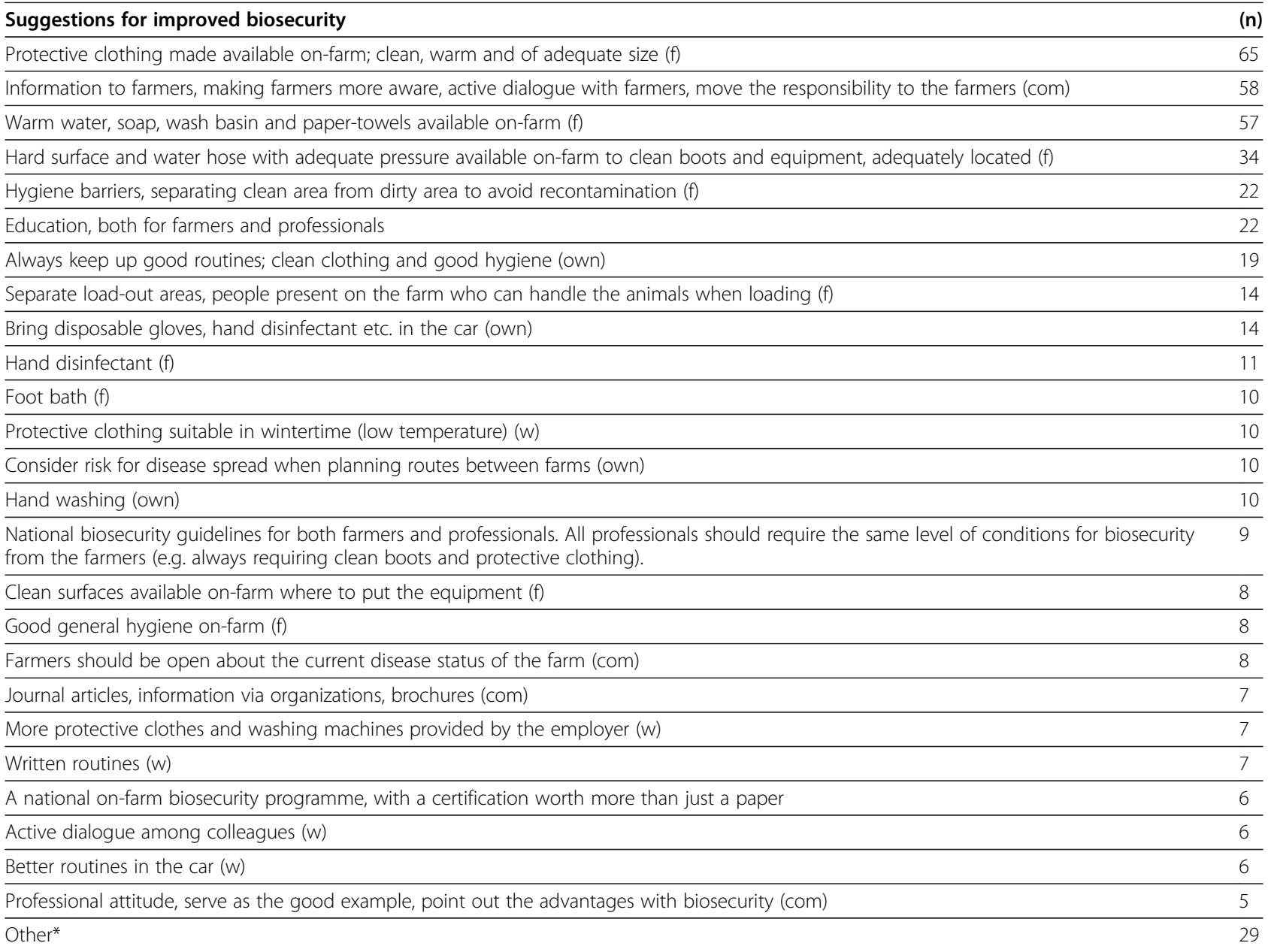

Based on an open ended question in a questionnaire to Swedish veterinarians, Al-technicians, animal welfare inspectors, livestock hauliers and hoof trimmers in 2012-2013.

$(\mathrm{f})=$ on-farm,$(\mathrm{w})=$ workplace, (com) $=$ communication.

${ }^{*}$ Other = Suggestions for improved on-farm biosecurity for visitors reported by less than five responders, for example: Storage boxes for used protective clothing in the car, Equipment available on the farm, e.g. for hoof trimming, Sign on the door, stating no entrance without permission from the farmer, Already when planning for new stables, biosecurity and disease prevention should be included, Have higher demands , "have the guts to speak up to farmers and colleagues", Provide financial incentives, Sell protective clothing and hand disinfectant to farmers, To clean equipment, Equipment that is easy to clean.

through specific programmes [29], and after eradication the routines are gradually relaxed, as was seen with Aujezsky's disease (Sweden was declared officially free in 1996 [30]). Except for an outbreak of PRRS in 2007 and two vector borne diseases (Bluetongue and Schmallenberg), Sweden has not had any large outbreak of an exotic animal disease for decades [29-32], this may have had a negative impact on farmer awareness.

Responsibility and expectancy seem to be key issues mentioned by several respondents both in this study and in another current study focusing on the farmers' perspectives (unpublished data). The visitors reported that the on-farm conditions did not allow an adequate level of biosecurity and that many farmers did not require any biosecurity routines, whereas farmers reported that they expect all visitors to be professional and take responsibility for not spreading any diseases. Recent national legislation in the area may help in clarifying the responsibilities [33] as well as the European Union proposal for a new Animal Health Law [7].

Several veterinarians reported that they had repeatedly asked farmers for improvements, but some concluded that veterinarians as a group have not been explicit enough. The benefits of veterinarians communicating messages about biosecurity to farmers, as well as farmers' preference for receiving biosecurity information from their veterinarian has been identified in other studies [8,18,19,34-36].

There were differences in the perceived conditions among different categories of visitors for the same 
category of farm. In part this can be explained by different types of farms visited, e.g. animal welfare inspectors visit another group of cattle farmers compared to AItechnicians. But there were also differences related to the task performed on the farm. For example, the animal welfare inspectors do not visit the farm at the farmer's request, but more likely the opposite. They found it difficult to demand anything at all, and were afraid to be blamed for any disease introduction. Another example was the livestock hauliers who suggested that hand hygiene facilities be provided where they enter the farm, not only at the entrance for other visitors. These aspects should be kept in mind when developing biosecurity recommendations for different categories of professionals.

Limited access to water and soap was a general problem. This is surprising since the need for hand hygiene is old knowledge, described by Semmelweis in 1847 [37]. There are situations, e.g. on pasture, with no access to running water, but this can easily be solved, as was suggested, by bringing a water container, soap and a clean bucket. Several of the participants in the study also reported efforts to keep their hands clean despite poor conditions on the farm, e.g. stopping at a gas-station to wash their hands or using hand disinfectants and wipes in the car. Not all visitors may make this extra effort, and the effects of hand disinfectants without prior washing may not be sufficient [38]. In the extensive work to improve hand hygiene in human health, accessibility has been identified as an important factor for compliance with hand washing and disinfection routines [37].

Some responses indicated a lack of understanding among farmers of how infectious disease agents can spread through indirect contact. There were numerous comments on how protective clothing, when provided, was cold, damp and dirty. Clothes and boots in poor condition will not be used and will not fulfil the purpose of avoiding contamination of the visitor. There is a problem if farmers believe clothes and boots in such poor conditions to be adequate, but this may not only be related to lack of understanding. There are other influencing factors, like personality traits, which are discussed in a Canadian study where farmers were observed taking biosecurity risks through reusing shoe protections from the garbage [21].

The poor biosecurity conditions reported for farms with horses are alarming and there is obviously room for improvement. Need for improvement of biosecurity among horse owners and horse practitioners has also been identified in other countries $[3,39,40]$

Salmonella was the disease that most respondents were afraid to spread between farms. This may be related to the farm restrictions in the Swedish salmonella control programme [41]. The other diseases mentioned reflected the endemic disease situation in Sweden.
However, some responses only included exotic animal diseases regulated by law. This may indicate an awareness of these diseases, but may also reflect an unawareness of the actual situation in Sweden. An increasing number of veterinarians in Sweden have a veterinary degree from abroad [42], from countries where these diseases may be endemic.

Several studies have concluded that people working with livestock are at higher risk of contracting zoonotic diseases and for colonisation with MRSA $[28,43]$. In our study, 44\% mentioned one or more zoonotic agents they were afraid to contract while working. From an Australian study it was reported that $35.3 \%$ of the veterinarians were concerned or very concerned for either themselves or for colleagues [27], but since the questions were asked in different ways these figures are not directly comparable. Ringworm was the disease that most persons mentioned as one of the diseases they were afraid to contract in their daily work, the same result was found in a study among veterinarians in the US [26]. Ringworm was also reported to be the most common zoonosis contracted by veterinarians both in Oregon and in South Africa [25,44] and is probably a highly relevant zoonosis in Sweden as well since it is endemic in livestock. Salmonella came in second place, although the prevalence of salmonella in Swedish livestock is quite low [41]. This high ranking could be due to absence of other severe zoonotic infections such as brucellosis and tuberculosis [29,30]. Multi-resistant bacteria and MRSA came in third place, although the prevalence is still believed to be low in Sweden [45]. There were also six persons stating that they were afraid to contract rabies, even though rabies was last confirmed in a Swedish animal in 1886 [30]. In recent years, however, there has been an increased illegal import of dogs to Sweden [46] and the fear of contracting rabies may be related to this.

This study used a convenience sample. Due to the distribution methods used, overall response rates cannot be assessed. How non-responders might differ from the responders, and the representativeness of the results, cannot be assessed either. It is possible that people with a particular interest in biosecurity, and perhaps frustrated by the lack of it, were more prone to answer the questionnaire, leading to a bias towards reporting poor biosecurity. Although persons with an interest in biosecurity may be overrepresented among the respondents, obstacles reported are likely to be generally present. However, the factors motivating biosecurity could be different among the non-respondents compared to the respondents. Despite these limitations, this study has captured views and opinions regarding on-farm biosecurity from groups of professionals where previously no information was available.

The many different (largely unknown) underlying factors affecting the types of farms visited and the uncertainty 
in the representativeness of both respondents and farms they visited was the reason for keeping to descriptive statistics, more advanced statistical methods would probably not be more informative.

There are a number of factors affecting biosecurity, both from the farmers' and from the visitors' perspectives. Lack of knowledge can be one reason for not implementing biosecurity routines [16]. However, human behaviour is complex and it is well known that not only knowledge is needed to change behaviour [47]. It is important also to understand the experienced obstacles and motivators for biosecurity. This study is part of a project in which farmers are also asked about hindrances and motivators for biosecurity. Trying to approach the on-farm biosecurity related to professionals visiting farms from two different perspectives will add to the understanding of this issue.

\section{Conclusions}

Many of the respondents reported obstacles for keeping adequate biosecurity related to on-farm conditions, and a large proportion of farms visited were reported to lack the very basics for visitors' biosecurity. Different visitors seemed to have different conditions for maintaining biosecurity on farms. There was a gap when it came to responsibility and this need to be clarified; visitors need to take responsibility for avoiding spread of disease, while farmers need to assume responsibility for providing adequate conditions for on-farm biosecurity.

\section{Additional files}

Additional file 1: Questionnaire, translated to English. Questionnaire regarding biosecurity to persons visiting farms in their profession, translated to English.

Additional file 2: Questionnaire, Swedish. Questionnaire regarding biosecurity to persons visiting farms in their profession, Swedish original version.

\section{Competing interests}

There were no competing interests.

\section{Authors' contributions}

MN and SS designed the study. MN developed the questionnaire, collected data, analysed the data and drafted the manuscript. SSL participated in the analyses of data and revised the manuscript. Both authors read and approved the final manuscript.

\section{Acknowledgements}

The project was funded by the Swedish Civil Contingencies Agency (MSB). We acknowledge all participants in the study and Svenska Veterinärförbundet, Veterinärer i Sverige, Växa, Skåne semin, Rådgivarna i Sjuhärad and Länsstyrelsernas djurskyddschefer that were willing to support the study by distributing the questionnaires within their organizations and we also acknowledge Jenny Frössling for valuable advice throughout the study. The Swedish Board of Agriculture is acknowledged for providing the data on registered livestock hauliers.

\section{Author details}

${ }^{1}$ Department of Disease Control and Epidemiology, SVA, National Veterinary Institute, Uppsala SE-751 89, Sweden. ${ }^{2}$ Department of Biomedical Sciences and Veterinary Public Health, SLU, Swedish University of Agricultural Sciences, Box 7028, Uppsala SE-750 07, Sweden.

Received: 13 August 2013 Accepted: 21 April 2014

Published: 9 May 2014

\section{References}

1. van Schaik G, Schukken YH, Nielen M, Dijkhuizen AA, Barkema HW Benedictus G: Probability of and risk factors for introduction of infectious diseases into Dutch SPF dairy farms: a cohort study. Prev Vet Med 2002, 54:279-289.

2. van Schaik G, Schukken YH, Nielen M, Dijkhuizen AA, Benedictus G: Risk factors for introduction of BHV1 into BHV1-free Dutch dairy farms: a case-control study. Vet Q 2001, 23:71-76.

3. Firestone SM, Lewis Fl, Schemann K, Ward MP, Toribio JA, Dhand NK: Understanding the associations between on-farm biosecurity practice and equine influenza infection during the 2007 outbreak in Australia. Prev Vet Med 2013, 11:028-36.

4. Ellis-Iversen J, Smith RP, Gibbens JC, Sharpe CE, Dominguez M, Cook AJ: Risk factors for transmission of foot-and-mouth disease during an outbreak in southern England in 2007. Vet Rec 2011, 168:128.

5. Ribbens S, Dewulf J, Koenen F, Maes D, de Kruif A: Evidence of indirect transmission of classical swine fever virus through contacts with people. Vet Rec 2007, 160:687-690.

6. Ohlson A, Heuer C, Lockhart C, Tråven M, Emanuelson U, Alenius S: Risk factors for seropositivity to bovine coronavirus and bovine respiratory syncytial virus in dairy herds. Vet Rec 2010, 167:201-206.

7. Proposal for a regulation of the european parliament and of the council on animal health swd(2013) 160 final. http://ec.europa.eu/food/animal/docs/ahlaw-proposal_en.pdf.

8. Gunn GJ, Heffernan C, Hall M, McLeod A, Hovi M: Measuring and comparing constraints to improved biosecurity amongst GB farmers, veterinarians and the auxiliary industries. Prev Vet Med 2008, 84:310-323.

9. Ribbens S, Dewulf J, Koenen F, Mintiens K, De Sadeleer L, de Kruif A, Maes D: A survey on biosecurity and management practices in Belgian pig herds. Prev Vet Med 2008, 83:228-241.

10. Valeeva NI, van Asseldonk MA, Backus GB: Perceived risk and strategy efficacy as motivators of risk management strategy adoption to prevent animal diseases in pig farming. Prev Vet Med 2011, 102:284-295.

11. Heffernan C, Nielsen L, Thomson K, Gunn G: An exploration of the drivers to bio-security collective action among a sample of UK cattle and sheep farmers. Prev Vet Med 2008, 87:358-372.

12. Costard S, Porphyre V, Messad S, Rakotondrahanta S, Vidon H, Roger F, Pfeiffer DU: Multivariate analysis of management and biosecurity practices in smallholder pig farms in Madagascar. Prev Vet Med 2009, 92:199-209.

13. Siekkinen KM, Heikkilä J, Tammiranta N, Rosengren $\mathrm{H}$ : Measuring the costs of biosecurity on poultry farms: a case study in broiler production in Finland. Acta Vet Scand 2012, 54:12.

14. Zhang YH, Li CS, Liu CC, Chen KZ: Prevention of losses for hog farmers in China: insurance, on-farm biosecurity practices, and vaccination. Res Vet Sci 2013, 95:819-24.

15. Kristensen $\mathrm{E}$, Jakobsen EB: Danish dairy farmers' perception of biosecurity. Prev Vet Med 2011, 99:122-129.

16. Sayers RG, Sayers GP, Mee JF, Good M, Bermingham ML, Grant J, Dillon PG: Implementing biosecurity measures on dairy farms in Ireland. Vet J 2013, 197:259-267.

17. Brennan ML, Christley RM: Biosecurity on cattle farms: a study in north-west England. PLoS One 2012, 7:e28139.

18. Simon-Grifé M, Martín-Valls GE, Vilar-Ares MJ, García-Bocanegra I, Martín M, Mateu E, Casal J: Biosecurity practices in Spanish pig herds: perceptions of farmers and veterinarians of the most important biosecurity measures. Prev Vet Med 2013, 110:223-231.

19. Hernández-Jover M, Taylor M, Holyoake $P$, Dhand N: Pig producers' perceptions of the Influenza Pandemic H1N1/09 outbreak and its effect on their biosecurity practices in Australia. Prev Vet Med 2012, 106:284-294.

20. Laanen M, Persoons D, Ribbens S, de Jong E, Callens B, Strubbe M, Maes D, Dewulf J: Relationship between biosecurity and production/antimicrobial treatment characteristics in pig herds. Vet J 2013, 198:508-512. 
21. Racicot M, Venne D, Durivage A, Vaillancourt JP: Evaluation of the relationship between personality traits, experience, education and biosecurity compliance on poultry farms in Quebec, Canada. Prev Vet Med 2012, 103:201-207.

22. Racicot M, Venne D, Durivage A, Vaillancourt JP: Evaluation of strategies to enhance biosecurity compliance on poultry farms in Quebec: effect of audits and cameras. Prev Vet Med 2012, 103:208-218.

23. Racicot M, Venne D, Durivage A, Vaillancourt JP: Description of 44 biosecurity errors while entering and exiting poultry barns based on video surveillance in Quebec, Canada. Prev Vet Med 2011, 100:193-199.

24. Nöremark M, Frössling J, Lewerin SS: Application of routines that contribute to on-farm biosecurity as reported by Swedish livestock farmers. Transbound Emerg Dis 2010, 57:225-236.

25. Gummow B: A survey of zoonotic diseases contracted by South African veterinarians. J S Afr Vet Assoc 2003, 74:72-76.

26. Wright JG, Jung S, Holman RC, Marano NN, McQuiston JH: Infection control practices and zoonotic disease risks among veterinarians in the United States. J Am Vet Med Assoc 2008, 232:1863-1872

27. Dowd K, Taylor M, Toribio JA, Hooker C, Dhand NK: Zoonotic disease risk perceptions and infection control practices of Australian veterinarians: call for change in work culture. Prev Vet Med 2013, 111:17-24.

28. Baker WS, Gray GC: A review of published reports regarding zoonotic pathogen infection in veterinarians. J Am Vet Med Assoc 2009, 234:1271-1278.

29. SVA (National Veterinary Institute): Sjukdomsrapportering 2011, En uppdatering av regeringsrapporten 2006. In SVA:s rapportserie 23 ISSN 1654-7098. ; 2012

30. SVA (National Veterinary Institute): Surveillance of infectious diseases in animals and humans in Sweden 2012. In SVA:S rapportserie 26 ISSN 1654-7098. ; 2013.

31. Carlsson $U$, Wallgren $P$, Renström LH, Lindberg A, Eriksson $H$, Thoren $P$ Eliasson-Selling L, Lundeheim N, Nörregård E, Thörn C, Elvander M: Emergence of porcine reproductive and respiratory syndrome in Sweden: detection, response and eradication. Transbound Emerg Dis 2009, 56:121-131.

32. Sternberg Lewerin S, Hallgren G, Mieziewska K, Berndtsson LT, Chirico J, Elvander M: Infection with bluetongue virus serotype 8 in Sweden in 2008. Vet Rec 2010, 167:165-170.

33. Jordbruksverket (Swedish Board of Agriculture): Statens jordbruksverks föreskrifter och allmänna råd om förebyggande och särskilda åtgärder avseende hygien m.m. för att förhindra spridning av zoonoser och andra smittämnen. I. In SJVFS 2013:14, K112. Jordbruksverket (Swedish Board of Agriculture); 2013.

34. Schemann K, Firestone SM, Taylor MR, Toribio JA, Ward MP, Dhand NK Horse owners'/managers' perceptions about effectiveness of biosecurity measures based on their experiences during the 2007 equine influenza outbreak in Australia. Prev Vet Med 2012, 106:97-107.

35. Garforth CJ, Bailey AP, Tranter RB: Farmers' attitudes to disease risk management in England: a comparative analysis of sheep and pig farmers. Prev Vet Med 2013, 110:456-466.

36. Brennan ML, Christley RM: Cattle producers' perceptions of biosecurity. BMC Vet Res 2013, 9:71

37. Hugonnet S, Pittet D: Hand hygiene-beliefs or science? Clin Microbiol Infect 2000, 6:350-356

38. Racicot M, Kocher A, Beauchamp G, Letellier A, Vaillancourt JP: Assessing most practical and effective protocols to sanitize hands of poultry catching crew members. Prev Vet Med 2013, 111:92-99.

39. Aceto H, Bender JB, Clark C, Daniels JB, Davis MA, Hinchcliff KW, Johnson JR, McClure J, Perkins GA, Pusterla N, Traub-Dargatz JL, Weese JS, Whittem TL: Report of the third Havemeyer workshop on infection control in equine populations. Equine Vet J 2013, 45:131-136.

40. Rosanowski SM, Rogers CW, Cogger N, Benschop J, Stevenson MA: The implementation of biosecurity practices and visitor protocols on non-commercial horse properties in New Zealand. Prev Vet Med 2012, 107:85-94.

41. Lewerin SS, Skog L, Frössling J, Wahlström H: Geographical distribution of salmonella infected pig, cattle and sheep herds in Sweden 1993-2010. Acta Vet Scand 2011, 53:51.

42. Jonsson P: Ledare: policydokument allt viktigare för veterinärkåren. Svensk Veterinärtidning 2013, 2:3.
43. Garcia-Graells C, Antoine J, Larsen J, Catry B, Skov R, Denis O: Livestock veterinarians at high risk of acquiring methicillin-resistant Staphylococcus aureus ST398. Epidemiol Infect 2012, 140:383-389.

44. Jackson J, Villarroel A: A survey of the risk of zoonoses for veterinarians. Zoonoses Public Health 2012, 59:193-201.

45. Unnerstad HE, Bengtsson B, Horn Af Rantzien M, Börjesson S: Methicillinresistant Staphylococcus aureus containing mecC in Swedish dairy cows. Acta Vet Scand 2013, 55:6.

46. Pressrelease, smuggling av hundvalpar stoppades,. http://www.jordbruksverket. se/formedier/nyheter/nyheter2012/smugglingavhundvalparstoppades.5. 5ce6c400139a12671c880001762.html.

47. Kollmuss A, Agyeman J: Mind the gap: why do people act environmentally and what are the barriers to pro-environmental behavior? Environ Educ Res 2002, 8:239-260.

doi:10.1186/1751-0147-56-28

Cite this article as: Nöremark and Sternberg-Lewerin: On-farm biosecurity as perceived by professionals visiting Swedish farms. Acta Veterinaria Scandinavica 2014 56:28

\section{Submit your next manuscript to BioMed Central and take full advantage of:}

- Convenient online submission

- Thorough peer review

- No space constraints or color figure charges

- Immediate publication on acceptance

- Inclusion in PubMed, CAS, Scopus and Google Scholar

- Research which is freely available for redistribution 